\title{
Relationship of Eating Behavior, Knowledge, Attitudes, Physical Activities, and Parent Support with Obesity Events in Adolescents in Padang City
}

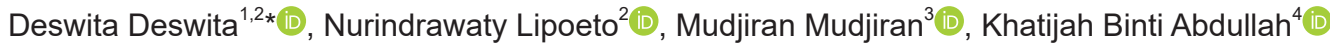 \\ ${ }^{1}$ Doctoral Program of Public Health, Faculty of Medicine, Universitas Andalas, Padang, Indonesia; ${ }^{2}$ Department of Pediatric \\ Nursing, Faculty of Nursing, Universitas Andalas, Padang, Indonesia; ${ }^{3}$ Department of Biomedic, Faculty of Medicine, Universitas \\ Andalas, Padang, Indonesia, ${ }^{4}$ Department of Guidance and Counseling, Faculty of Education, University of State, Sunway \\ University, Kuala Lumpur, Malaysia
}

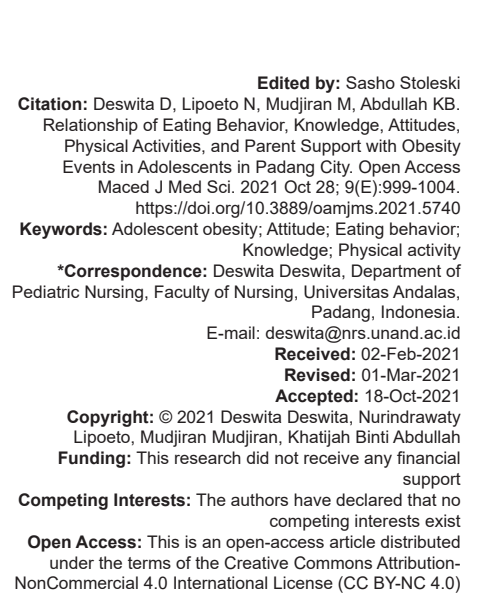

\section{Abstract}

BACKGROUND: A report from the West Sumatra Provincial Health Office in December 2017 showed increase in the percentage of overweight and obese children in the city of Padang. In 2014, overweight children amounted to $4.86 \%$ and an increase in 2016 to $6.44 \%$.

AIM: This study aimed to determine the most dominant risk factors affecting the incidence of obesity in adolescents in Padang City.

MATERIALS AND METHODS: This study was conducted on 484 respondents from 4 (four) schools, namely SMPN 26, SMPIT Adzkia, SMAN 3, and SMA Adabiah Padang in December 2019-February 2020. Data analysis used the Chi-square test and multiple logistic regression tests.

RESULTS: The multivariate analysis results showed that adolescents' eating behavior variable was the most dominant factor affecting adolescents' incidence of obesity with a significance value of $p<0.05$ and Exp (B) 14.11 These results showed that adolescents who behave eat poorly at 14.11 times, have the risk of obesity more than adolescents who eat well.

CONCLUSIONS: Adolescent eating behavior variables can predict the incidence of obesity in adolescents together with adolescent physical activity variables, adolescent attitudes, and adolescent knowledge.

\section{Introduction}

Child obesity is currently a severe problem that is being considered to improve public health status. In the world, the number of children who are obese has increased 10-fold in the last four decades. If this trend continues, there will be more children and adolescents with obesity in 2022, according to a study conducted by Imperial College London and the World Health Organization [1].

Various data showed that obesity prevalence tends to increase every year in both developed and developing countries, particularly obesity which occurs in adolescents. More than 340 million children and adolescents aged 5-19 years were overweight and obese in 2016. Increased the prevalence of overweight and obesity in children and adolescents had increased dramatically from 4\% in 1975 to more than $18 \%$ in 2016 (WHO, 2018) [2]. According to Pengpid and Peltzer research, in 2016, the data was collected on overweight and obesity in several
ASEAN countries: Malaysia 23.7\%, Philippines 10.2\%, Thailand $8.9 \%$, and Indonesia $7.0 \%$ [3]. This prevalence associated with several factors: developed and developed countries, consumption of healthy foods and nutrients such as vegetables, and physical activity such as cycling [3].

A report from the West Sumatra Provincial Health Office in December 2017 showed that an increase in the percentage of children who are overweight and obese in the city of Padang. In 2014, overweight children amounted to $4.86 \%$ and an increase in 2016 to $6.44 \%$. Based on data from student enrollment in West Sumatra Province in 2016 revealed that overweight and obese children occurred mostly in junior high school children about $9.93 \%$ compare than primary school children $5.94 \%$ and high school children $3.84 \%$ (Report from the West Sumatra Provincial Health Office, 2017 [4]).

Obesity preventive action will reduce government funding for catastrophic diseases as a result of obesity. Obese adolescents will form noncommunicable diseases such as diabetes and 
cardiovascular disease which spent a high burden on funding for health care in developing countries. Obesity will impact adolescent physical health, leads hypertension, hyperlipidemia, glucose intolerance, decreased insulin sensitivity, mental health disorders (depression, low self-esteem), and (in the long term, it will have an impact on decreasing the quality of life) in long term will impact on decreasing quality of life. When someone is obese since childhood, then most likely will also be obese in adulthood. Another impact, obesity in adolescents will be prone to diabetes and heart disease which will significantly reduce the quality of life of adolescents, besides that the incidence of obesity will reduce the life expectancy of adolescents 2-19 years to be shorter when compared to the life expectancy of adolescents who are not obese [5].

Therefore, it is necessary to know the risk factors that influence the incidence of obesity in adolescents. Thus, interventions for the prevention and control of obesity in adolescents can be carried out on target populations. This study aimed to determine the most dominant risk factors affecting the incidence of obesity in adolescents in Padang City.

\section{Methods}

This research conducted at both secondary school students (SMP and SMA) in Padang City by providing a questionnaire that had been tested before. This questionnaire distributed to 484 respondents at different times and places. Each respondent filled out the questionnaire individually at the same time. The questionnaire's distribution carried out by following the learning schedule for each class's guidance and counseling subjects. Its distributed to 4 (four) schools at SMPN 26, SMPIT Adzkia, SMAN 3, and SMA Adabiah Padang, started from December 2019 to February 2020. The distribution of questionnaires involved several teachers in each school. The questionnaire used multiple choice questions with ordinal scale which is already has a standard score in each variable. Then, score that obtained was classified for each categories in each variable.

The bivariate analysis, in this study, aims to determine the relationship between the variables of adolescent eating behavior, adolescent knowledge, adolescent attitudes, adolescent physical activity, parental support, and gender on the incidence of obesity in adolescents in Padang City in 2020. The bivariate analysis uses the Chi-square test. Meanwhile, the dominant factor that affects the incidence of obesity used through multivariate analysis. All variables resulting from bivariate analysis with a $p<0.25$ were included in the multivariate analysis using multiple logistic regression tests. The data analyzed with IBM SPSS Statistic 23 Version.

\section{Results}

The results of the study found that most of the respondents $(69.6 \%)$ were female. Most of the respondents $(41.0 \%)$ were student from SMA Adabiah. Most of the respondents were in grade 10 (33.7\%) and grade $11(29.9 \%)$. The data of BMI was collected by questionnaire. The distribution of respondents according to $\mathrm{BMI}$ classification is presented in Table 1.

Table 1: Distribution of respondents by BMI classification

\begin{tabular}{lll}
\hline BMl classification & $F$ & $\%$ \\
\hline Underweight & 146 & 30.2 \\
Normal & 251 & 51.9 \\
Overweight & 31 & 6.4 \\
Obesity & 56 & 11.6 \\
Total & 484 & 100.0 \\
\hline
\end{tabular}

Table 1 showed that there are $56(11.6 \%)$ of the respondents who were obese. Then, there were $31(6.4 \%)$ of the overweight respondents at risk of obesity. Meanwhile, $30.2 \%$ respondents were in underweightcategory. Mostly, theunderweightrespondents were in 11-12 years old. Usually, growth acceleration would be happen after puberty (12-13 years old).

The results of statistical tests of the influence of eating behavior, knowledge, attitudes, physical activity, and gender on the incidence of obesity in adolescents in Padang City can be seen in Table 2.

Table 2: Effect of eating behavior, knowledge, attitudes, physical activity, parental support, and gender on the incidence of obesity in adolescents in Padang City in $\mathbf{2 0 2 0}$

\begin{tabular}{|c|c|c|c|c|c|c|c|c|}
\hline \multirow[t]{2}{*}{ Risk factors } & \multicolumn{2}{|c|}{ Obesity } & \multicolumn{2}{|c|}{ Not obesity } & \multicolumn{2}{|c|}{ Total } & \multirow[t]{2}{*}{$\mathrm{p}$-value } & \multirow[t]{2}{*}{ OR $(95 \% \mathrm{Cl})$} \\
\hline & $\bar{f}$ & $\%$ & $\bar{f}$ & $\%$ & $\bar{f}$ & $\%$ & & \\
\hline \multicolumn{9}{|c|}{ Eating behavior } \\
\hline It's risky & 48 & 85.7 & 118 & 27.6 & 166 & 34.3 & \multirow[t]{3}{*}{$<0.001$} & \multirow{3}{*}{$15.763(7.2-34.3)$} \\
\hline No risk & 8 & 14.3 & 310 & 72.4 & 318 & 65.7 & & \\
\hline Total & 56 & 100 & 428 & 100 & 484 & 100 & & \\
\hline \multicolumn{9}{|c|}{ Feeding knowledge } \\
\hline Low & 40 & 71.4 & 152 & 35.5 & 192 & 39.7 & \multirow[t]{3}{*}{$<0.001$} & \multirow[t]{3}{*}{$4.539(2.5-8.4)$} \\
\hline High & 16 & 28.6 & 276 & 64.5 & 292 & 60.3 & & \\
\hline Total & 56 & 100 & 428 & 100 & 484 & 100 & & \\
\hline \multicolumn{9}{|c|}{ Eating attitude } \\
\hline Negative & 46 & 82.1 & 174 & 40.7 & 220 & 45.5 & \multirow[t]{3}{*}{$<0.001$} & \multirow[t]{3}{*}{$6.715(3.3-13.7)$} \\
\hline Positive & 10 & 17.9 & 254 & 59.3 & 264 & 54.5 & & \\
\hline Total & 56 & 100 & 428 & 100 & 484 & 100 & & \\
\hline \multicolumn{9}{|c|}{ Physical activity } \\
\hline Low & 20 & 35.7 & 67 & 15.7 & 87 & 18.0 & \multirow[t]{3}{*}{$<0.001$} & \multirow[t]{3}{*}{$2.993(1.6-5.5)$} \\
\hline High & 36 & 64.3 & 361 & 84.3 & 397 & 82.0 & & \\
\hline Total & 56 & 100 & 428 & 100 & 484 & 100 & & \\
\hline \multicolumn{9}{|c|}{ Parental support* } \\
\hline Low & 43 & 76.8 & 212 & 50.5 & 255 & 53.6 & \multirow[t]{3}{*}{$<0.001$} & \multirow[t]{3}{*}{$3.245(1.7-6.2)$} \\
\hline High & 13 & 23.2 & 208 & 49.5 & 221 & 46.4 & & \\
\hline Total & 56 & 100 & 420 & 100 & 484 & 100 & & \\
\hline \multicolumn{9}{|l|}{ Gender } \\
\hline Female & 41 & 73.2 & 296 & 69.2 & 337 & 69.6 & \multirow[t]{3}{*}{0.641} & \multirow[t]{3}{*}{$1.219(0.7-2.3)$} \\
\hline Male & 15 & 26.8 & 132 & 30.8 & 147 & 30.4 & & \\
\hline Total & 56 & 100 & 428 & 100 & 484 & 100 & & \\
\hline
\end{tabular}

Table 2 shows that there are $85.7 \%$ of obese adolescents have risky eating behavior. Meanwhile, adolescents who are not obese, only $27.6 \%$ have risky eating behavior. The Chi-square test results obtained $p<0.001$. It can be concluded that there was a significant relationship between eating behavior and the incidence of obesity in adolescents in Padang City in 2020. The adolescents who have a risk of eating behavior are 15.763 times more likely to be obese than adolescents who have no risk of eating behavior. 
Table 2 also shows that $71.4 \%$ of obese adolescents have insufficient knowledge (low). Meanwhile, adolescents who are not obese, only $35.5 \%$ have insufficient knowledge. Chi-square test results obtained a $p<0.001$. There is a significant relationship between the level of knowledge and obesity in adolescents in Padang City in 2020. Adolescents with low knowledge are 4.539 times more likely to be obese than adolescents with high knowledge.

As much as $82.1 \%$ of obese adolescents have a negative attitude. Meanwhile, $40.7 \%$ of adolescents who were not obese were negative. The chi-square test results obtained $p<0.001$. It can be concluded that there is a significant relationship between attitudes and the incidence of obesity in adolescents in Padang City in 2020. Adolescent with negative attitude are 6.715 times more likely to be obese than adolescents with positive attitude (Table 2).

As much as $35.7 \%$ of obese adolescents have low physical activity. Meanwhile, $15.7 \%$ of adolescents who were not obese have low physical activity. Chi-square test results obtained a $p<0.001$. There is a significant relationship between physical activity and obesity in adolescents in Padang City in 2020. Teens with low physical activity are 2.993 times more likely to be obese than adolescents with high physical activity (Table 2).

About $76.8 \%$ of obese adolescents have low parental support. Meanwhile, adolescents who are not obese are only $50.5 \%$ with low parental support. The Chi-square test results obtained a $p<0.001$. It can be concluded that there is a significant relationship between parental support and the incidence of obesity in adolescents in Padang City in 2020. Adolescents with low parental support are 3.245 times more likely to be obese than adolescents with high parental support (Table 2).

As much as $73.2 \%$ of obese adolescents are female. These data were not much different for adolescents who are not obese, where $69.2 \%$ are female. The Chi-square test results obtained $p=0.641$. There is no significant relationship between gender and the incidence of obesity in adolescents in Padang City in 2020 (Table 2).

The dominant factor affecting obesity in adolescents in Padang City in 2020 can be identified through multivariate analysis. Multivariate analysis was used to determine predictor variables that can predict the dependent variable and its strong predictive potential. All variables resulting from bivariate analysis with a $p<0.25$ were be included in the multivariate analysis, for this multivariate analysis using multiple logistic regression tests.

After selecting candidate variables to build a predictive model, then multivariate analysis was carried out with multiple logistic regression tests, the analysis used to see the effect of each dominant variable on the incidence of obesity in adolescents, then the model selection used the enter method; if the analysis was bivariate, the variable has a $p>0.05$, then gradually the variables are eliminated one by one, starting with the variable with the highest value. This model has applied again so that each variable has a value of $p<0.05$. The final results of multiple logistic regression tests could be seen in Table 3 below.

Table 3: Dominant factors affecting the incidence of obesity in adolescents in Padang City in 2020

\begin{tabular}{llll}
\hline Predictor variable & Regression coefficient & p-value & OR 95\% Cl (Lower-Upper) \\
\hline Constant & -1.382 & $0.001^{*}$ & - \\
Adolescent eating behavior & 2.647 & $<0.001^{*}$ & $14.113(6.1-32.7)$ \\
Knowledge youth & 1.268 & $0.001^{*}$ & $3.554(1.7-7.3)$ \\
Attitude youth & 1.535 & $<0.001^{*}$ & $4.641(2.1-10.2)$ \\
Physical activity youth & 1.594 & $<0.001^{*} 4.922(2.2-10.8)$ \\
\hline "There is a significant relationship $(\mathrm{p}<0.05)$. & &
\end{tabular}

The multivariate analysis results in Table 3 show that adolescents' eating behavior variable is the most dominant factor affecting the incidence of obesity in adolescents with a significance value $<0.05$ and Exp (B), namely 14,113 . These results indicated that adolescents who eat poorly behave at 14,113 times the risk of obesity than adolescents who eat well. Adolescent eating behavior variables can predict obesity in adolescents and adolescent physical activity variables, adolescent attitudes, and adolescent knowledge.

\section{Discussion}

Based on this study results, there was a significant relationship between eating behavior and the incidence of obesity in adolescents in Padang City in 2020. Adolescents who have risk of eating behavior are 15.763 times more likely to be obese than adolescents who have no risk of eating behavior. The study's statistical test results had a significance level of $p=0.005$ using the Pearson Chi-square test with a prevalence ratio of 3.00 (95\% Confidence Interval 1.303-6.905). Obesity is a noncommunicable disease that can provide many complications in the future. The cause of obesity in adolescents is multifactorial, one of which is diet. Abhigamika et al. (2019) also found [6] that diet has a significant influence on a unidirectional relationship to the occurrence of adolescent obesity in high school students in Denpasar. Therefore, it is crucial to maintain a diet to prevent obesity in adolescents so that it needs to be considered especially for adolescents themselves and their families and communities [6].

Based on the results of research conducted by Candra et al. 2016, there is a significant relationship between diet and obesity $(p=0.05)$ [7]. Obese adolescents tend to choose foods with high calories and in large quantities. Obese adolescents are accustomed to repeatedly eating each type of food because they have a large appetite. Obese adolescents tend to feel hungry more quickly than normal adolescents due to 
their eating habits. The habit of consuming food in excess or large enough quantities is a factor affecting obesity. In addition to large portions of food, obese adolescents also tend to have a habit of snacking in their spare time. They often feel still hungry if they eat normal food portions [7].

Research result Mokolensang and Manampiring, 2016 as well showed that overall, there is a very significant relationship between diet, in this case, the intake of energy, carbohydrates, protein, and fat with obesity status $(p<0.01)$ [8]. In other words, the diet explored in this study can be said to be one of the risk factors for obesity in the subjects in this study. This data confirmed by the logistic regression analysis results, which shows that from the various nutritionals intake. Fat intake is the variable that most influences the obesity status of the subjects, in this study, diet, in this case, is the intake of energy, carbohydrates, protein, and fat $(\operatorname{Exp}(B)=6, p<0.01)$. Research in America showed that the group with high fat intake had a greater risk of weight gain than the low-fat group [9]. Other studies have shown that an increase in meat consumption will increase the risk of obesity by 1.46 times [10]. This situation is due to the fat foods have a greater energy density and are less filling and have a smaller thermogenesis effect than foods high in protein and carbohydrates. Fatty foods also have a very delicious taste that will increase appetite, leading to excessive consumption [8].

This study found a significant relationship between the level of knowledge and the incidence of obesity in adolescents in Padang City in 2020. Adolescents with low knowledge were 4.539 times more likely to be obese than adolescents with high knowledge. The level of knowledge of students in choosing snack foods affects their attitudes in choosing consumed snack foods. With good knowledge, it is hoped that students will choose healthy and nutritionally balanced snacks. Efforts to prevent and manage obesity in adulthood and adolescence emphasize nutritional information/knowledge, appropriate snack foods, and calorie reduction methods. The assumption underlying this approach is that lack of understanding or lack of knowledge can lead to weight gain. One of the factors that influence obesity is a lack of knowledge about the nutritional value [11]

The existence of new information about healthy snacks provides a new cognitive basis for the formation of knowledge in selecting healthy snacks. Knowledge can be obtained outside of school, such as through the media and information from parents. Knowledge of street food is essential to study because it is an internal factor that affects street food consumption. Knowledge is very influential in the selection of street food. Knowledge can be acquired both internally and externally. Internal knowledge comes from itself based on life experience, while externally is the knowledge that comes from other people so that knowledge about street food increases. Adequate knowledge is expected to affect the consumption of good food so that it can lead to a good nutritional status. Insufficient knowledge about nutrition and mistakes in choosing snack foods will affect nutritional status, such as obesity [11].

However, the data is not in line with research in Noviyanti and Marfuah (2017), which showed no significant relationship between nutritional knowledge and adolescent nutritional status [12]. The cause of the absence of a relationship between knowledge, and nutritional status is because knowledge is an indirect influence on nutritional intake. The presence of infectious diseases and nutritional intake has a direct effect on nutritional status. Good nutritional knowledge does not always underlie nutritious food choices, habits and purchasing power still influence this. This study did not track the purchasing power of the family [12].

This study found a significant relationship between attitudes and the incidence of obesity in adolescents in Padang City in 2020. Adolescents with negative attitudes were 6.715 times more likely to be obese than positive adolescents. This data was by following per under research conducted on students of SMAN 2 Jember, showed a significant relationship between student attitudes toward the habit of consuming fast food with the incidence of obesity, following with a significant influence between predisposing factors (attitudes) on a diet in research in a private school (level of energy intake) of female students [11].

Attitude is not yet an action or activity, but it is a predisposition to action or behavior. Attitude is the readiness to react to objects in a particular environment as an appreciation of the object. An appropriate attitude does not necessarily lead to good eating habits. Person's attitude can be formed by the presence of social interactions that can affect individuals. Attitude consists of positive and negative attitudes. A person's attitude toward food is much influenced by others' experiences and responses to food since childhood so that each individual can have a like or dislike attitude toward food. The attitude of adolescents in choosing snack foods is also greatly influenced by personal experience, relationships with the people closest to them, parents and peers, and the culture in their family and environment. The impact caused by these factors can change a positive attitude to a negative one. School-age children will usually imitate the attitude of their parents. If their parents' attitude in choosing snacks is selective or disciplined by prioritizing their health, the child will imitate the attitude of their parents in choosing snacks at school. The attitude that is formed can affect adolescents in choosing snack foods, which can also impact their nutritional status. Teens generally tend to consume energy-rich snack foods that come from carbohydrates and fats.

This study found a significant relationship between physical activity and obesity in adolescents 
in Padang City in 2020. Adolescents with low physical activity were 2.993 times more likely to be obese than adolescents with high physical activity. This data was in line with the research results conducted by Candra et al. (2016) that there was a significant relationship between physical activity and obesity $(p=0.01)$ [7]. Physical activity causes burning energy so that the more adolescents do activities, and more energy is used. This study's results are in line with the studies conducted by Sherwood et al. Physical activity can burn fat and calories according to the type of physical activity. If someone is in the inactive category, the body's fat and calorie content will accumulate without any burning process. Conversely, obesity can also affect physical activity. High body mass can trigger people to be lazy to do activities and prefer sleeping, sitting, or resting and eating [7].

However, this data is not in line with the research Noviyanti and Marfuah (2017), which shows no significant relationship between physical activity and adolescent nutritional status [12]. Although statistically, there is no relationship in this study; it does not mean that physical activity does not affect adolescent nutritional status. Physical activity is one of the factors that determine adolescent nutritional status. Physical activity is the movement of the limbs that causes energy expenditure, which is essential for maintaining a healthy physical, mental, and living life. Physical activity level is a physical activity category based on the amount of energy expended for that type of activity per unit time in $24 \mathrm{~h}$. Other research stated that most teenagers have a physical activity that is less than recommended. The physical activity level is very briefly, including spending more time on activities in a standing position, being quiet, or sitting down. Low physical activity is a risk factor for obesity; the interaction between eating a lot and low physical activity can cause obesity.

Less active adolescents have a high risk of obesity. Obesity in adolescence also has an impact on adolescent psychosocial development. Obese adolescents often get psychological violence from the environment to become less confident, sad, nervous, and lonely. Lack of physical activity causes much energy to be stored as fat, so people who do not do enough exercise tend to get fat. This data explained that the level of physical activity contributes to excess body weight, especially the habit of continually sitting, watching television, using computers and other high-tech tools (or sit down). Low physical activity is a risk factor for obesity, the interaction between eating a lot, and low physical activity can cause obesity. This data explains that the level of physical activity contributes to excess body weight, especially the habit of continually sitting, watching television, using computers and other high-tech tools (or sit down). Low physical activity is a risk factor for obesity; the interaction between eating a lot and low physical activity can cause obesity. Less active adolescents have a high risk of obesity. Obesity in adolescence also has an impact on adolescent psychosocial development. Obese adolescents often get psychological violence from the environment to become less confident, sad, nervous, and lonely. Lack of physical activity causes much energy to be stored as fat, so people who do not do enough tend to get fat.

This data explains that the level of physical activity contributes to the incidence of excess body weight. The habit of continually sitting, watching television, using computers and other high-tech tools or Low physical activity is a risk factor for obesity). The interaction between eating a lot and low physical activity can cause obesity. Less active adolescents have a high risk of obesity. Obesity in adolescence also has an impact on adolescent psychosocial development. Obese adolescents often get psychological violence from the environment to become less confident, sad, nervous, and lonely. Lack of physical activity causes much energy to be stored as fat, so people who do not do enough tend to get fat. This data explained that the level of physical activity contributes to excess body weight, especially the habit of continually sitting, watching television, using computers and other high-tech tools. Low physical activity is a risk factor for obesity, the interaction between eating a lot, and low physical activity can cause obesity. Less active adolescents have a high risk of obesity. Obesity in adolescence also has an impact on adolescent psychosocial development. Obese adolescents often get psychological violence from the environment to become less confident, sad, nervous, and lonely. Lack of physical activity causes much energy to be stored as fat, so people who do not do enough tend to get fat. This data explained that the level of physical activity contributes to excess body weight, especially the habit of continually sitting, watching television, using computers, and other high-tech tools [12].

Based on the results of this study proved that a significant relationship between parental support and the incidence of obesity in adolescents in Padang City in 2020. Adolescents with low parental support were 3245 times more likely to develop obesity than adolescents with high parental support. Parents must always educate their children to choose safe snacks by bringing supplies chosen and prepared food by themselves. Parents can also show children hygienic and healthy places to buy food, for example, in school canteens that meet hygiene requirements. Usually, at school, children choose snacks sold on the side of the road or near the school. Teach children to choose snacks that are clean, free of flies, whose sellers maintain personal hygiene, and food packaging is safe. If necessary, occasionally come to the school environment and observe which snacks are safe for school children.

Snacks must meet the nutritional balance requirements needed by the body to be able to do 
activities. Snacks must contain balanced portions of carbohydrates, protein, fat, vitamins, and minerals. A nutritionally balanced diet is essential for optimal growth in children and as the foundation for a healthy life for the future. There is no one perfect food that can meet all the nutritional needs of a person. Therefore, food must be varied, so that the need for each nutrient is met. Advise children not to choose only one type of snack (occasionally come to the school environment and observe which snacks are safe for school children. Snacks must meet the nutritional balance requirements needed by the body to be able to do activities. Snacks must contain balanced portions of carbohydrates, protein, fat, vitamins, and minerals. A nutritionally balanced diet is essential for optimal growth in children and as the foundation for a healthy life for the future.

There is no one perfect food that can meet all the nutritional needs of a person. Therefore, food must be varied, so that the need for each nutrient is met. Advise children not to choose only one type of snack (occasionally come to the school environment and observe which snacks are safe for school children). Snacks must meet the nutritional balance requirements needed by the body to be able to do activities. Snacks must contain balanced portions of carbohydrates, protein, fat, vitamins, and minerals. A nutritionally balanced diet is essential for optimal growth in children and as the foundation for a healthy life for the future. There is no one perfect food that can meet all the nutritional needs of a person. Therefore, food must be varied, so that the need for each nutrient is met. Advise children not to choose only one type of snack balanced portions of vitamins and minerals. A nutritionally balanced diet is essential for optimal growth in children and as the foundation for a healthy life for the future. There is no one perfect food that can meet all the nutritional needs of a person. Therefore, food must be varied, so that the need for each nutrient is met. Advise children not to choose only one type of snack (balanced portions of vitamins and minerals. A nutritionally balanced diet is essential for optimal growth in children and as the foundation for a healthy life for the future. There is no one perfect food that can meet all the nutritional needs of a person. Therefore, food must be varied, so that the need for each nutrient is met. Advise children not to choose only one type of snack [13].

It is essential to maintain a diet to prevent obesity in adolescents so that it needs to be considered especially for adolescents themselves and their families and communities. Parents, schools, and health workers can educate children to choose safe snacks, show children hygienic and healthy places to buy food, and invite children to do physical activities.

\section{Conclusions}

Adolescent eating behavior is the most dominant factor affecting the incidence of obesity in adolescents. Adolescent eating behavior variables, adolescent physical activity variables, adolescent attitudes, and adolescent knowledge are significantly correlated to obesity in adolescents.

\section{References}

1. Majid M. Differences in the level of nutritional knowledge, body image, energy intake, and nutritional status of nutritional and non-nutritional students, the Faculty of Health, Muhammadiyah University of Parepare. Sci J Man Health. 2018;1(1):24-33. https://doi.org/10.20884/1.jgps.2018.2.2.1382

2. World Health Organization. Obesity. Geneva: World Health Organization; 2018.

3. Pengpid S, Peltzer K. Overweight, obesity, and associated factors among 13-15 years old students in the Association of Southeast Asian Nations member countries, 2007-2014. S Asian J Trop Med Public Health. 2016;47(2):250. https://doi. org/10.1016/j.ajp.2017.01.019

PMid:27244964

4. West Sumatra Provincial Health Office Report; 2017.

5. Wille N, Bullinger M, Holl R, Hoffmeister U, Mann R, Goldapp C, Ravens-Sieberer U. Health-related quality of life in overweight and obese youths: Results of a multicenter study. Health Qual Life Outcomes 2010;8(1):36. http://doi.org/10.1186/1477-7525-8-36 PMid:20374656

6. Abhigamika NA, Adnyana WL, Sudhana IW. The Relationship between Diet and Adolescent Obesity in High School Students (SMA) in Denpasar; 2019.

7. Candra A, Wahyuni TD, Sutriningsih A. Relationship between physical activity and diet with the incidence of obesity in adolescents in SMA laboratorium malang. Nurs News 2016;1(1):1-6.

8. Mokolensang OG, Manampiring AE. The relationship between diet and obesity in adolescents in bitung city. Biomedical 2016;4(1):33-41.

9. Johnson L, Mander AP, Jones LR, Emmett PM, Jebb SA Energy-dense, low-fiber, high-fat dietary pattern is associated with increased fatness in childhood. Am J Clin Nutr 2008;87(4):846-54. http://doi.org/10.1093/ajcn/87.4.846 PMid:18400706

10. Fukuda S, Takeshita T, Morimoto K. Obesity and lifestyle. Asian Med J 2001;44(3):97-102.

11. Sukma DC, Margawati A. Relationship between Knowledge and Attitudes in Choosing Snack Food with Obesity in Adolescents at SMP Negeri 2 Brebes (Doctoral Dissertation, Diponegoro University); 2014.

12. Noviyanti RD, Marfuah D. The Relationship between Nutritional Knowledge, Physical Activity, and Diet on Adolescent Nutritional Status in Purwosari Laweyan Village, Surakarta, Urecol; 2017. p. 421-6

13. Sembiring N. Relationship between parental support and factors affecting snack eating behavior at SD muhammadiyah 1 Pekanbaru city. J Healthy Prosperous Families 2018;16(1):51-9. 